Chair for Management Sciences and Energy Economics University of Duisburg-Essen

EWL Working Paper No. 1

\title{
DECENTRALIZED ENERGY SUPPLY AND ELECTRICITY MARKET STRUCTURES
}

by

Christoph Weber

and

Philip Vogel

November 2005 


\title{
Decentralized energy supply and electricity market structures
}

\author{
by Christoph Weber and Philip Vogel
}

\begin{abstract}
Small decentralized power generation units (DG) are politically promoted because of their potential to reduce GHG-emissions and the existing dependency on fossil fuels. A long term goal of this promotion should be the creation of a level playing field for DG and conventional power generation. Due to the impact of DG on the electricity grid infrastructure, future regulation should consider the costs and benefits of the integration of decentralized energy generation units. Without an adequate consideration, the overall costs of the electricity generation system will be unnecessarily high. The present paper analyses, based on detailed modelling of decentralized demand and supply as well as of the overall system, the marginal costs or savings resulting from decentralized production. Thereby particular focus is laid on taking adequately into account the stochasticity both of energy demand and energy supply. An efficient grid pricing system should then remunerate long-term grid cost savings to operators of decentralized energy production or/and charge long-term additional grid costs to these operators. With detailed models of decentralized demand and supply as well as the overall system, the marginal costs or savings resulting from decentralized production are determined and their dependency on characteristics of the grid and of the decentralized supply are discussed.
\end{abstract}

Keywords : electricity markets, decentralized power production, demand side management JEL-Classification : Q40, Q42, L94, L98, 033

PROF. DR. CHRISTOPH WeBER

Chair for Management Sciences and Energy Economics, University of Duisburg-Essen (Campus Essen)

Universitätsstr. 11, 45117 Essen

++49 - (0)2 01 / 183-2966

www.ewl.wiwi.uni-due.de

christoph.weber@uni-due.de
DIPL.-VOLKSW. PHILIP VOGEL

Chair for Management Sciences and Energy Economics, University of Duisburg-Essen (Campus Essen)

Universitätsstr. 11, 45117 Essen

++49 - (0)2 01 / 183-3399

www.ewl.wiwi.uni-due.de

philip.vogel@uni-due.de

The authors are solely responsible for the contents which do not necessarily represent the opinion of the Chair for Management Sciences and Energy Economics. 


\section{Introduction}

From an environmentalist perspective, decentralized power production and demand side management are often seen as key options to move towards a more sustainable energy system (cf. e.g. Pepermans et al. 2005, El-Khattam and Salama 2005, Raineri et al. 2005, Lovins 2003). Thereby, decentralized power production or Distributed Generation includes production from renewable sources as well as small-scale combined heat-andpower production (CHP). Large-scale wind farms by contrast are usually not considered to fulfil the criterion of decentralized power production - although they clearly contribute to saving GHG emissions.

In recent years, it has turned out that the fixed feed-in tariffs used so far in Germany and other countries for promoting renewables are rather effective in as far as the number of installed units is concerned. But at the same time it has become obvious that this type of regulation does not provide efficient signals both for short-term operation and longterm investment in renewables and decentralized power production units. One key issue is that the power producers are only partly rewarded for savings in grid costs, which may result from decentralized production, nor penalized for additional grid costs which may result for locally concentrated renewables (such as large-scale wind). If renewables and decentralised production are to contribute efficiently to mitigating climate change, this aspect of grid and market regulation has to be dealt with adequately.

In the last years, there has been a broad debate on the theory and application of efficient network pricing concepts in the electricity industry (cf. the recent surveys by Brunekreeft et al. 2005, Joskow 2005, Salerian et al. 2001). Although issues of distributed generation and demand side management have been repeatedly mentioned in these analyses, this debate has remained widely disconnected of the debate on distributed generation $^{1}$. In particular a detailed analysis of the potential benefits or costs of distributed generation to the grid has only be undertaken for a nodal pricing system (Hadley et al. 2005) and the resulting implications for network pricing have not been analyzed so far. Obviously the application of locational pricing would be the first-best solution. Yet considerable efforts and transaction costs would be necessary for the implementation of such pricing at the level of distribution grids. Thus, on beforehand a detailed analysis

\footnotetext{
${ }^{1}$ A notable exception is the analysis by Brunekreeft and Ahlers (2005), which however largely focuses on the problem of ownership unbundling and incentives for investment into Distributed Generation.
} 
based on the characteristics of the grid and the distributed generation technologies seem advisable.

Therefore, the present paper aims at analysing the potential grid effects of distributed generation based on a bottom-up system modelling approach. Also demand side management (DSM) is partly considered, since both options have the same impact when long run grid cost savings are considered: On site generation of electricity during peak load allows a smaller dimensioning of the higher voltage network capacities as does peak shaving through DSM. Based on detailed modelling of decentralized demand and supply as well as the overall system, the marginal costs or savings resulting from decentralized production or demand side management are determined and their dependency on characteristics of the grid and of the decentralized supply are discussed. Thereby it is important to take adequately into account the stochasticity both of overall energy demand and energy supply. An efficient grid pricing system should then remunerate long-term grid cost savings to operators of decentralized energy technologies or/and charge long-term additional grid costs to these operators.

The paper is correspondingly organised as follows. In the following first the rationale for introducing distributed generation and the potential benefits it may deliver are briefly recapitulated. Then a bottom-up approach is developed for assessing the value of the potential benefits. Thereby not only theoretical relationships are derived but also some estimates of magnitude based on German available data are given. Based on these considerations, then the implications for grid charges are discussed.

\section{Potential benefits of distributed generation}

Today's energy systems are mainly centrally organised and power is transported mostly unidirectionally from big power plants to consumers of energy. Moreover, the ongoing liberalisation of electricity markets leads to a division of electricity transport and generation, which leaves potential economies of scope of combined planning of generation and transmission behind. At the same time, recent technological developments and specific promotion policies are favouring the expansion of distributed technologies and might ultimately lead to a hybrid system with actively managed decentralised units (cf. the papers collected in a special issue of the Energy Journal: Sharma and Bartels, 1997; Either and Mount, 1997; Morse, 1997; Pfeifenberger et al., 1997; but also Preston et al., 1996; Bendel and Nestle 2005, and others). 
There exists no general definition of distributed generation (Wohlgemuth 2001) but commonly it is understood that distributed generation units (DG), like combined heat and power generation units (CHP), fuel cells, biogas plants, micro turbines, small wind turbines, or solar cells are connected to the grid at a low or medium voltage level $(<100$ $\mathrm{kV}$ ) and do not exceed certain power limits ${ }^{2}$. Sometimes not only smaller power plants are considered as DG sources, but also all local options for energy management. This includes several technological possibilities like energy storages and demand side management. Due to the fact that the argument of the following sections applies mostly for DSM and decentralised energy supply, we stay with this definition which sees DSM as a part of the DG concept. In this view DG-facilities have the potential to increase the system flexibility and effectiveness by supply and demand side management, have often a higher degree of energy efficiency and can lower dependencies on fossil fuels. But the crucial question is, if these advantages can be reached at a level of acceptable cost.

The integration of DG-technologies is confronted with technical problems related to spatial distribution, grid stability, power supply quality and other issues. Some facilities like solar cells or wind turbines also have to face stochasticity of energy generation. As a result of technical innovation and newly developed tools, like storage technologies, electronic communication devices, or wind forecasting tools, these technical barriers become less restrictive (e.g. Bendel 2004; Lehman 2005). Notwithstanding these progresses however the issue of economic viability remains to be investigated.

The potential economic benefits of distributed generation include:

1. lower scheduled (resp. spot market) energy use in the central system ${ }^{3}$ and decrease in required generation capacities

2. lower regulating power needs in the central system

3. lower grid costs in the high voltage (transmission) grid

4. lower grid costs in the low and medium voltage (distribution) grid These have to be weighted against

5. increased/decreased operation and investment costs in distributed generation

6. specific costs for connecting the distributed generation plants to the grid. The valuation of the first two terms is rather easy in competitive markets, since this may be done on the basis of spot and regulating power market prices (cf. e.g. Weber and Vo-

\footnotetext{
${ }^{2}$ But Preston and Rastler (1996) include even power plants with a capacity of more than 100 MW within DG and many sources do not quantify any power limit, e.g. IEA (2002).

3 This obviously does not hold for pure load shifting Demand Side Management as explained above
} 
gel 2007). Also the last two points are easily dealt with based on plant-wise cost-benefit calculations (e.g. Sander 2004, Auer et al. 2004, Weber 2006).

Yet the grid related benefits of distributed generation and demand side management are more difficult to assess since there exist no appropriate markets - at least in continental Europe. Locational pricing as applied in some US electricity markets (e.g. Kumar et al. 2005; Smeers 2005) will also be of little help, since this is usually only done at the level of transmission grid nodes.

Under these circumstances the only viable approach for assessing the potential benefits of distributed generation is bottom-up modelling. Thereby it has to be taken into account that the grid benefits of DG are rather diffuse and distributed and thus not easily quantifiable. They will moreover depend very much on the specific constellation of any particular grid under study.

\section{Assessment of potential grid benefits}

Savings in grid costs can either be associated with capital cost savings or with operation cost savings. Especially for the capital costs it is key, whether they are determined under the assumption of a constant grid topology or whether potential changes in the grid appearance and connections are taken into account. Besides cost savings resulting from lower transportation needs in the grid also the effects of DG on ancillary services provided by the grid such as power harmonics, voltage stabilization or phase angle may be considered. However, the focus in the following will be on the transportation and energy related benefits.

Concerning the DG technologies, a key distinction has to be made between those, where the energy output is controllable (notably CHP) and those relying on fluctuating sources, notably wind and solar power production. Of course also the latter may be controlled by introducing wind (or solar) shedding, yet this will only be the ultimate recourse, if problems with system stability are imminent. Otherwise their output will always be maximised given that they produce at zero variable costs. For these generation technologies savings in grid costs are less likely, given that the fluctuations in their power production correlate only partly, if at all, with variations in power consumption. Therefore the following considerations focus on the case of controllable DG sources, i.e. mostly CHP technologies given that for CHP technologies economic and ecological efficiency are usually higher than for non-CHP DG technologies. 
Savings in operation costs of electricity grids can then be a result of the following effects:

1. reduction in grid losses

2. reduction in demand for balancing energy

Savings in capital expenditures may occur as a consequence of:

3. reduction of investment in local grids

4. reduction of investment in higher level grids

These potential grid benefits of distributed generation will be assessed in the following in order to derive sound implications for tariff structures.

\subsection{Operational savings - reduction in grid losses}

With on-site generation of electricity, transportation losses in higher level grids can be reduced or avoided. This avoidance reduces the total required supply of electricity for meeting demand and should be credited to the DG-facilities as they are responsible for this reduction in system costs. The transmission of electrical current in actual networks causes losses $l_{i}$ as summarized in table 1, which are determined by the laws of physics for the different voltage levels i. An approximate way for calculating the economical value of avoided costs for transportation losses $C_{L o}$ is to use an average transportation distance $d_{i}$ (e.g. Haubrich, Hoffmann, (1995) for the German grid), the market price of electricity $p_{t}$, the above mentioned loss factor $l_{i}$, which is assumed here to be time independent, and the transported power $q_{t}$ :

Table 1: Transportation losses and average transportation distances at different voltage levels

\begin{tabular}{|c|c|c|}
\hline Voltage level & Transportation losses per 100km & Average distance [km] \\
\hline High & $0,2 \%$ & 100 \\
\hline Medium & $7 \%$ & 60 \\
\hline Low & $10 \%$ & \\
\hline
\end{tabular}

Source: Materazzi-Wagner, Ch. (2003), Haubrich, H.-J.; Hoffmann, J. (1995)

$$
C_{L o}=\sum_{i} d_{i} l_{i} \sum_{t} p_{t} q_{t}
$$


However in reality the losses rather depend on the square of the power transmitted (e.g. Stoft 2002) - thus instead of (1) one should rather write

$$
C_{L o}=\sum_{i} d_{i} z_{i} \sum_{t} p_{t} q_{t}^{2}
$$

With instantaneous power expressed as a fraction of total energy transmitted

$$
q_{t}=f_{t} Q
$$

a weighted electricity price can be defined as:

$$
\tilde{p}=\frac{\sum_{t} p_{t} f_{t}^{2}}{\sum_{t} f_{t}^{2}}
$$

Then the avoided losses can be expressed as a function of the total electricity transmitted:

$$
C_{L o}=\sum_{i} d_{i} z_{i} \tilde{p} Q^{2}
$$

The marginal costs savings attributable to avoided losses are then obtained by derivation of (5):

$$
\frac{\partial C_{L o}}{\partial Q}=2 \tilde{p} Q \sum_{i} d_{i} z_{i}=2 \frac{C_{L o}}{Q}
$$

This holds under the assumption that the marginal power transmitted (or avoided) follows the same load profile as the bulk transmission. The weighted electricity price $\tilde{p}$ is $53.2 € / M W h$ for Germany in 2006 (EEX (2007)). With average grid losses of $4.4 \%$, the marginal avoided losses through DG are $4.7 € / \mathrm{kWh}$ per unit of DG production. Losses in the low voltage grid are not accounted for in these calculations, given that also the DG often uses the local grid. These benefits are generated in the short run and don't affect investment decisions to the grid. For DSM also a reduction of grid losses and resulting costs may be observed. Yet this is a consequence of changing the fractions $f_{t}$ of the total energy transmitted. Levelling out the fractions reduces obviously the sum of squares. Moreover in as far as high prices correlate with high load, the reduction of high loads also reduces the average cost of the losses. 


\subsection{Operational savings - reduction in demand for balancing energy}

Balancing energy is used by the grid operator to compensate for unforeseen variations in demand or production. The amount required depends not only on the stochasticity of supply and demand but also on the time lag between the closing of the spot market and the actual operating hours. So far this time lag in the Nordic and the Continental European Markets is 12 to $36 \mathrm{~h}$, given that bids for the spot market have to be submitted until noon of the previous day. Balancing energy is today always activated by the transmission grid operator, partly automatically (in the UCTE system: primary and secondary reserve) and partly manually (tertiary or minute reserve). On the one hand, when electricity demand exceeds supply, positive balancing energy is needed, which can be provided by conventional power plants but also by DG. Another possibility is the reduction of load by DSM. If, on the other hand, supply is larger than demand (e.g. due to the emergence of unexpected wind) conventional or distributed generation has to be lowered or the demand is increased through DSM measures.

A potential reduction in balancing energy requirements through DG depends on the operation mode of any distributed generation. If the units are run in order to maximise their energy output, they will usually not contribute to minimizing grid imbalances. This requires a local energy management (cf. e.g. Büchner 2005). This local energy management can basically be run with one of two possible strategies:

- either with the objective to reduce the local imbalances in the building or distribution grid, where the distributed generation is implemented

- or with the objective of reducing the overall imbalance in the higher voltage area, to which the distribution grid is connected.

Operators of distributed generation may now either chose to offer balancing services to the transmission grid operator or their units could be used to reduce imbalances at a lower level - be it at the building level or the level of the low voltage grid.

At first sight the second alternative seems attractive since it corresponds to the view of the distributed generation serving the "local needs". Yet a look at the stochasticity of demand rapidly makes clear that this is not such an easy task. Figure 1 shows a typical load curve of a single household. One can identify peaks in demand up to $7 \mathrm{~kW}$, whereas the average load is about $0.3 \mathrm{~kW}$, leading to an average load factor of $4 \%$. The maximum needs for regulating power are in the same order of magnitude than the demand peaks, 
given that on a day-ahead basis the exact usage of the kettle or the electric hob will be very difficult to predict.

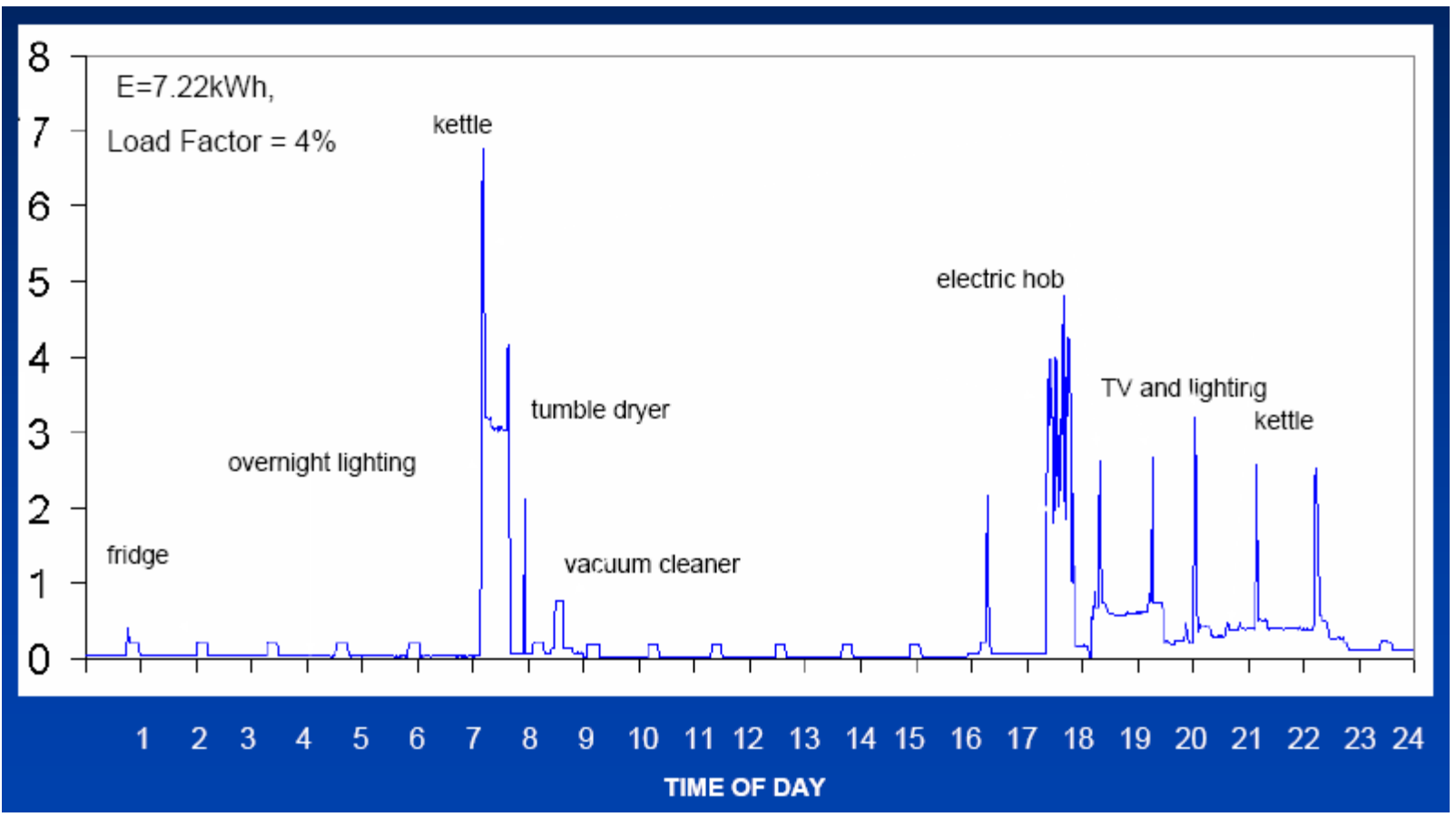

Source: Newborough (wo y.)

Figure 1: Typical load curve of a single household

If DG were to equalize these local demand peaks, huge capacities would have to be installed, which would remain idle most of the time.

According to the law of large numbers, the ratio of peak demand to average demand is rapidly decreasing, if a larger number of customers is considered. If the stochastic variations between households are fully uncorrelated, the standard deviation of load is in the same order of magnitude than the load itself for a local grid of 100 households, whereas it is about 10 times the load for a single household given that the standard deviation increases only with the square root of the number of the independent stochastic variables, whereas the sum increases linearly (cf. table 2). With four million households - a typical number for a transmission grid - load variation will be less than $1 \%$ if the deviations are fully uncorrelated. And also in reality a typical load forecasting error is in the order of $2 \%$ (e.g. Hufendiek 1999). 
Table 2: Average and standard deviation of load for different customer groups - according to the law of large numbers

\begin{tabular}{|l|l|l|l|}
\hline Customer group & $\begin{array}{l}\text { Average Load } \\
\mathrm{E}[\mathrm{L}]\end{array}$ & $\begin{array}{l}\text { Standard devia- } \\
\text { tion of load } \sigma(\mathrm{L})\end{array}$ & $\begin{array}{l}\text { Variation coeffi- } \\
\text { cient } \mathrm{V}(\mathrm{L})=\sigma(\mathrm{L}) / \\
\mathrm{E}[\mathrm{L}]\end{array}$ \\
\hline Single household & $\approx 0.3 \mathrm{~kW}$ & $\approx 2 \mathrm{~kW}$ & $\approx 7$ \\
\hline $\begin{array}{l}\text { Low voltage grid, } \\
100 \text { households }\end{array}$ & $\approx 30 \mathrm{~kW}$ & $\approx 20 \mathrm{~kW}$ & $\approx 0.7$ \\
\hline $\begin{array}{l}\text { Small transmission grid } \\
\text { zone, } 4 \text { mio. households }\end{array}$ & $\approx 1200 \mathrm{MW}$ & $\approx 4 \mathrm{MW}$ & $\approx 0.003$ \\
\hline
\end{tabular}

Consequently, distributed generation will most effectively contribute to reducing balancing cost if it is used to compensate overall imbalances at the transmission grid level. Any balancing at lower levels will at least part of the time rather increase the overall imbalance than decrease it.

Even if this is the theoretically most efficient way of using DG for reducing balancing energy needs, the following obstacles have to be considered:

- Transmission system operators usually define minimum lot sizes for balancing energy bids - currently in Germany the bids in the reserve markets must be minimum $2 \mathrm{MW}$ for primary reserve and even minimum of $15 \mathrm{MW}$ for minute reserve. 4

- TSOs express concerns on the reliability of reserves provided by decentralised units - be it on the supply side or on the demand side.

- The provision of the system-wide balancing energy requires the provision of online system balance signals to the distributed generation units

- In the case of grid bottlenecks, system reserves can possibly not be provided by local operators.

The first three issues are mainly issues of transaction costs. Costs of handling small bids, of ensuring their reliability and of providing the necessary information to the distributed units will lower the benefits of distributed balancing energy. Yet if these transaction costs are neglected, still an upper bound for the benefits of decentral balancing energy provision can be derived. The fourth issue is more fundamental, since it implies

\footnotetext{
${ }^{4}$ In order to reduce this obstacle for DG, the limit was recently halved from 30 to $15 \mathrm{MW}$.
} 
that a reduction of grid connecting capacities as discussed below will hamper at least in some situations the possibility of balancing energy provision by distributed generation. But also in this case, an additive superposition of savings will provide an upper bound on possible benefits from DG.

For a CHP unit in Germany, the potential benefits from providing balancing energy can be estimated at about $50 € / \mathrm{kW}$ per year (cf. Weber and Vogel 2007), if the distributed units have full information on the current system imbalance. If the units have only local information, the value of balancing energy depends on the correlation between local and system-wide imbalance, but is usually much lower.

\subsection{Investment savings - reduction in local grid capacity}

When less electricity has to be transported through the grid, the grid capacities and thus the corresponding investments may be reduced, too. In the local grid, the following elements are key cost drivers:

- Transformers (connection points to higher voltage level)

- Switches and protections

- Lines

- House connections

Transformers and all the electrical protection and switching equipment are nowadays often combined in compact substations, where the key cost component is however the cost of the transformer. For low voltage lines, the key cost component is not the capacity of the line but the cost of digging it into the earth or putting it into the air. Therefore savings can mostly be achieved by reducing the line length. For house connections, the costs are again to some extent depending on the capacity installed.

The numbers given e.g. by Haubrich and Hoffmann (1995) illustrate that there are considerable economies of scale. The limiting factor for the size of the substations is often the impedance of the corresponding lines, which is mostly depending on their length. The key question is then, whether or to what extent the number of substations may be reduced through distributed generation.

The cost for substations $C_{T r \text {,ges }}$ in the grid may be generally written:

$$
C_{T r, g e s, D G}=n_{T r} C_{T r}\left(P_{T r, \max }\right)
$$


Hereby $n_{T r}$ stands for the number of substations in an investigated area; $C_{T r}$ describes the costs of one single transformer, which depends on its maximum capacity $P_{T r \text {, max }}$.

Two limiting cases may then be considered: under some circumstances, the number of substations may not be reduced at all with the introduction of DG, even if DG reduces the peak load to be covered by each substation. One reason for this case might be the $n-1$ criterion, which states that security of supply has to be given if any component of the grid is not available. This case is here labelled "Long-term with constant grid topology". The other extreme is that the number of substations can be adapted so that the average rated power per substation is remaining constant. This is called here "long-term with flexible grid topology". Both cases are theoretical boundaries, with the first however being most likely to occur if the grid owner has no incentives to optimise the structure of an existing grid. The second one can be attained only if the distribution of house connections allows a redistribution of local substations. This is notably not the case if a small isolated area (a small village) is served by one substation without any further low voltage grid in the vicinity.

The cost savings in both cases strongly depend on the reduction of transformer peak load through distributed generation. Traditionally, this reduction is often handled through so-called simultaneity factors, which describe the simultaneous occurrence of various loads. For local generation, the simultaneity factor should describe the generation, which can be relied on at the moment of peak load. A more detailed probabilistic approach determines the transformer capacity such that the probability of transformer overload does not exceed a pre-specified level. This is done in the following using simplifying assumptions.

For a single DG source in a local grid, the power provided reliably clearly is zero, given that also a DG source may undergo planned revision or unforeseen outage. For a local grid with $n_{D G}$ power sources $\left(n_{D G}>30\right)$ with identical characteristics and independent unavailability, however the available power is approximately normally distributed. If $r_{D G}$ is the probability of availability, the expected value for the available power output is $\mathrm{E}\left[P_{D G}\right]=n_{D G} r_{D G} P_{0}$, with $P_{0}$ the rated power output of a single DG unit. The standard deviation of available power is $\sigma\left[P_{D G}\right]=\sqrt{n_{D G} r_{D G}\left(1-r_{D G}\right)} \cdot P_{0}$. For the load also a normal distribution with expected value $\mathrm{E}[L]$ and standard deviation $\sigma(L)$ is assumed. Without DG, the transformer will be dimensioned to cope with a peak load of

$$
P_{T r, \max , 0}=E[L]+N(\rho) \sigma(L)
$$


with $N($ ) describing the distribution function of the standard normal and $\rho$ being a prespecified reliability level.

With DG present, the stochastic load flow over the transformer is $P_{T r}=L-P_{D G}$. If available DG units will produce (or avoid load) in the case of peaking load, the transformer can be dimensioned at:

$$
P_{T r, \max , D G}=E\left[P_{T r}\right]+N(\rho) \sigma\left(P_{T r}\right)
$$

Under the aforementioned assumptions of stochastic independence we have

$$
\sigma\left(P_{T r}\right)=\sqrt{\sigma^{2}(L)+n_{D G} r_{D G}\left(1-r_{D G}\right) P_{0}^{2}}
$$

The marginal change in required transformer capacity for an additional unit of DG is then

$$
\begin{aligned}
\frac{\partial P_{T r, \max , D G}}{\partial n_{D G}} & =-r_{D G} P_{0}+\frac{1}{2 \sqrt{\sigma^{2}(L)+n_{D G} r_{D G}\left(1-r_{D G}\right) P_{0}^{2}}} r_{D G}\left(1-r_{D G}\right) P_{0}^{2} \\
& =-r_{D G} P_{0}\left(1-\frac{\left(1-r_{D G}\right) P_{0}}{2 \sqrt{\sigma^{2}(L)+n_{D G} r_{D G}\left(1-r_{D G}\right) P_{0}^{2}}}\right)
\end{aligned}
$$

For small DG units, i.e. $P_{0} \ll \sigma(L)$, the reduction in necessary transformer capacity is approximately equal to the on average available DG power $r_{D G} P_{0}$, given that in this case the second term in the bracket is much smaller than 1 . This is of course an optimistic version, since it relies on the assumption that the DG units are running permanently, if they are available, or alternatively that they can be put online sufficiently fast to cope with sudden peaks. Also further electro-technical restrictions, stemming e.g. from black-start ability or voltage drop limits, are not taken into account here.

Inserting equation (9) into the cost equation (7) and deriving with respect to the DG power we get for the long term with constant grid topology using equation (11):

$$
\frac{\partial C_{T r, g e s, D G}}{\partial P_{D G}}=-\left.\frac{d C_{T r}}{d P_{T r}}\right|_{\frac{L_{g e s}-P_{D G}}{n_{T r}}} r_{D G}\left(1-\frac{\left(1-r_{D G}\right) P_{0}}{2 \sqrt{\sigma^{2}(L)+\frac{P_{D G}}{n_{T r}} r_{D G}\left(1-r_{D G}\right) P_{0}}}\right)
$$

In the long-term with flexible grid topology case, the power of each transformer has to be taken as constant. Then the number of substations $n_{T r}$ has to be adapted to match the total load minus reliable DG generation. This leads (in a slightly simplified way) to: 


$$
\frac{\partial C_{T r, \text { ges }, D G}}{\partial P_{D G}}=-\frac{C_{T r}\left(P_{T r, \max }\right)}{P_{T r, \text { max }}} r_{D G}\left(1-\frac{\left(1-r_{D G}\right) P_{0}}{2 \sqrt{\sigma^{2}(L)+\frac{P_{D G}}{n_{T r, 0}} r_{D G}\left(1-r_{D G}\right) P_{0}}}\right)
$$

In this case, the cost savings are thus proportional to the average cost per unit of transformer capacity of the substation instead of being proportional to the marginal cost.

The marginal cost savings for local substation investments can be estimated at 10 to 15 $€ / \mathrm{kW}$, corresponding to an annuity of 0.65 to $0.99 € / \mathrm{kW} / \mathrm{a}$ under the assumptions of a 40 year lifetime and an interest rate of $6.5 \%$. The average cost by contrast is almost four times higher.

For household connections no similar cost savings can be expected. Given that there will be usually only one DG unit per building and this unit can break down, the capacity of the household connection can hardly be reduced. Also for the grid lines, substantial savings are unlikely. With constant topology, the line length won't change anyhow. And with flexible topology, exemplary calculations show also that the line length is almost proportional to the size of the area deserved by a substation and thus DG does not provide any reduction in length.

Given that the operational costs of the low voltage grid consist mostly of maintenance costs and those are strongly depending on the number of entities to be maintained, there will be savings in operational costs only in the case of flexible topology and there also only in the case of the substations. The maintenance and operation costs are estimated at about $6 \%$ to $8 \%$ of the investment costs for transformers and lines (cf. Haupt et al. 2005). In a flexible grid topology case this leads under the aforementioned assumptions to savings of about 2.4 to $4.8 € / \mathrm{kW} / \mathrm{a}$.

\subsection{Investment savings - reduction in higher level grid investment}

For higher level grid investments, the same reasoning can be basically applied as for the low voltage grid. However the higher level grids are usually built as meshed grids, in order that the $n-1$ criterion is fulfilled. In this case it can be shown that wider meshes in a flexible topology setting also induce some reductions in line lengths. 


\section{Tariff structures for DG integration}

Due to the fact that DG facilities cause new benefits and costs to the grid, the operators of these technologies should be compensated or penalised in an adequate manner, incentives for efficient operation of all facilities should be built up and external effects to the grid should be internalised. In the following theoretical aspects based on the grid benefits identified in the previous section are discussed first. Then these are contrasted with the German practice.

\subsection{Theoretical aspects}

An important characteristic of the grid is its natural monopoly character, which means that marginal cost pricing is not sufficient to cover the costs of electricity distribution. This has lead to the development of second-best price concepts, which allow the monopolist to recover his costs by taking into account average costs instead focusing exclusively on marginal costs (cf. e.g. Berg and Tschirhart 1988). Among these concepts, multipart tariff systems are the most widely used in power markets, differentiating between a charge for capacity and distribution costs and one or more charges for actual energy consumption (Salies and Price, 2004). Whereas the capacity charge should include the overhead costs from the grid, the energy rate enables costumers to take the true costs of additional energy purchase into account. Another widely discussed principle for second best-pricing is the approach developed by Ramsey. Here price discriminating charges are set in accordance to the demand elasticity of single consumers. Those consumers with an inelastic demand contribute a higher share of their consumer surplus to the overhead costs of the grid than consumers with an elastic demand.

Based on this principle one can argue that DG and other generation technologies should not bear much of the general grid costs, given that their supply resp. demand reduction is rather price-elastic ${ }^{5}$. However, DG technologies should be in any case charged those costs, which can be directly associated with their operation, e.g. grid connection costs. This corresponds to the application of "shallow charges", as discussed by Scheepers (2004). 'Shallow charges' of DG system integration only include the direct effects like grid accession, while the concept of 'Deep charges' also takes indirect effects into ac-

\footnotetext{
5 This corresponds to the current practice in Germany and many other European countries, where generators are not charged any general grid costs.
} 
count. This requires that the distributed generators are attributed all the grid benefits resp. costs, which they are causing. In reality this approach is hardly realizable, because the benefits and costs of DG depend strongly on the location and the timing of investments. For example, grid cost savings can only be achieved in the short run if congestion occurs. Nevertheless, it should be tried to incorporate all external effects of DG in an efficient grid tariff system, in order to create the right incentives for investment.

Based on the discussion in the previous section, the following components of an efficient grid tariff system for DG have to be distinguished:

- Remuneration for balancing energy delivered resp. charges for deviations from the prescheduled power delivery, based on time-variable market prices for balancing energy

- Remuneration for reduced grid losses, based on time-variable spot market prices

- Remuneration for reduced local grid costs, notably reduced transformer capacity,

- Remuneration for reduced grid costs at higher levels, notably reduced transformer capacity and line lengths

- Charges for directly attributable grid connection costs, based on actual costs incurred.

Whereas current market prices can and should be taken for the first two elements, the pricing of the factors three and four is more difficult to do. Both the measurement of the availability and of the costs avoided is not that easily done. For the availability, the key point is which period(s) is defined as the peak period to be taken as basis for the determination of empirical availability. For the costs avoided in principle one of two alternatives could be applied: on the one hand the specific avoided costs for the local grid, where the DG is placed. On the other hand an average remuneration is possible, which is applied independently of the local conditions. The advantage of the latter approach clearly is the lower calculation effort. Moreover the long-term benefits in specific locations are rather difficult to determine given the wide range of uncertainties. On the other hand, the investment signals provided by such an approach are rather blurred. Especially in situations where DG could relief actual current weaknesses of the existing grid, it would not get the right investment signals.

Thus a two-part remuneration scheme seems most appropriate: if DG relieves actual grid weaknesses, it should be rewarded according to the costs avoided. In all other cases, a general remuneration rate is to be used. The weighted average of the two remuneration types should then correspond to the average avoided grid costs. 
In the context of grid regulation and ownership unbundling of distribution grids, it might also be desirable to create a tariff structure which gives incentives to DSOs to provide information on the sites which are most valuable for the attachment of DG and the application of DSM. This could happen within an approach which includes DG-units in the concepts of grid regulation. Thereby, it is desirable to let the DSOs take part from some benefits of DG.

\subsection{Current regulation in Germany}

Paragraph 18 of the EC directive on electricity markets (European Commission 2003) states that national authorities should take account of the long term avoided marginal network costs from DG.

Until 2005, the treatment of DG-facilities at the low-voltage level was regulated in the German "Verbändevereinbarung” (VDN (2001a), VDN (2001b)), which tried to establish Deep Charges and focused on the actually avoided costs. This approach was more or less in line with the reasoning of this article, yet with a focus on short term avoided costs like reduction in losses and need for balancing energy. However it was strongly criticized (cf. Mühlstein 2003) and therefore the legislation was changed with the introduction of the reformulated German energy law (BMWi 2005). From now on DG-operators were compensated with the full avoided grid costs, based on tariffs consumers had to pay for higher level grids. In $\S 14(2)$ of this law it is stated as general rule that TSOs and DSOs have to consider DG options when planning grid structures; $\$ 24$ states that avoided costs have to be reimbursed. Another issue is that the newly established German regulator (Bundesnetzagentur) is authorized to control the behaviour of TSOs and DSOs regarding DG-operators (§35). The energy law thus provides general principles on the treatment of distributed generation. The concrete handling of DG is settled in the order for electricity grid fees (StromNEV). Here it is written in $\S 18$ that TSOs have to compensate DG-operators with avoided costs in upstream grid levels. When DG units are promoted through the renewables energy act (EEG) or the cogeneration modernisation act (KWKG), no compensation is foreseen. The basis for remuneration is actual avoided energy delivered measured in kWh and actual capacity installed measured in kW. The avoided capacity installed is calculated from the output of the DG unit during the yearly peak demand. The reimbursement tariffs are equivalent to the rates electricity consum- 
ers are charged for network usage. Without meter reading only the reduction in energy delivered is compensated.

The results from the bottom up analysis of the upper sections of this paper suggest that this policy tends to overestimate the value of distributed generation, because it does not take scale effects of grid investment into account. On the other hand the current regulation contains a number of simplifications which might lead to an underestimation of the avoided costs. Here a more detailed investigation is necessary.

\section{Final remarks}

Determining the cost savings induced through distributed generation requires the consideration of different indirect effects. The analysis has shown that these effects lead to marginal costs which should be priced in a differentiated way in an efficient tariff system. To provide adequate investment and operation signals, notably costs/benefits for balancing energy should be treated separately from avoided transmission grid losses. Also avoided grid investment costs constitute a separate issue, where it is key to clarify how flexible the grid topology can be in the longer run. A first best approach for the treatment of DG would be the introduction of deep charges based on nodal prices which take all externalities into account. Unfortunately deep charges are hardly feasible, due to high transaction costs, timing and informational issues. For this reason a simplified tariff structure seems desirable, which considers all benefits and costs on average.

The existing regulation in Germany by contrast provides a rather easy to handle method, but fails to take into account all grid effects of DG-facilities correctly. It neglects scale effects of grid investments and does not consider the value of DG correctly. If electricity demand is reduced by DG, capital costs have to be allocated to smaller amounts of transported electricity, which increases the average grid costs per transmitted kWh.

\section{References}

Auer, H.; Huber, C., et al. (2004): Cost and Technical Constraints of RES-E Grid Integration, Greennet WP 2 available under: http://www.greennet.at/downloads/WP2\%20Report \%20GreenNet.pdf (05.10.2005). 
Bartels, R.H.; Sharma, D. (1997): Distributed electricity generation in competitive energy markets: A case study in Australia', Energy Journal, DR Special Issue, pp. 17-39.

Bendel, C. (2004): Vom Stromkunden zum Energiehändler - Startschuss für die Entwicklung des automatischen dezentralen Energiemanagers im Niederspannungsnetz, available under: $\quad$ http://www.iset.uni-kassel.de/abt/FBA/dinar/Data/presse300404.pdf

Bendel, C.; Nestle, D. (2005): Decentralized Electrical Power generators in the low voltage grid - development of a technical and Economical integration strategy, International Journal of Distributed Energy resources, 1(1), pp. 63 - 71.

Berg, S. V., Tschirhart, J. (1988): Natural monopoly regulation, principles and practice, Cambridge et al.

Brunekreeft, G.; Neuhoff, K.; Newberry,D. (2005): Electricity transmission an overview of the current debate, Utilities Policy, Volume 13(2), pp. 73-93; 2004.

Brunekreeft, G.; Ahlers, E. (2005): "Does ownership unbundling of the distribution networks distort the development of distributed generation?" available under: http://www.tilburguniversity.nl/tilec/publications/reports/repdgunb.pdf (29.01.2007)

BMWi (2005): Gesetz über die Elektrizitäts- und Gasversorgung (Energiewirtschaftsgesetz -

EnWG), available under: http://bundesrecht.juris.de/bundesrecht/ enwg_2005/gesamt.pdf (29.01.2007).

EEX (2007): EEX Handelsergebnisse Spotmarkt ,available under: http://www.eex.com (07.08.2007).

El-Khattam, W.; Salama, M.M.A. (2004): Distributed generation technologies, definitions and benefits, Electric Power Systems Research, Volume 71(2), Pages 119-128, 2004.

Ethier, R. and Mount, T. (1997): Winners and Losers in a Competitive Electricity Industry: An Empirical Analysis, The Energy Journal, DR Special Issue, pp 161-186. European Commission (2003): Directive 2003/54/EC of the European parliament and of the

council concerning common rules for the internal market in electricity and repealing 
Directive 96/92/EC, available under:_http://europa.eu.int/eurlex/pri/en/oj/dat/2003

/l 176/1 17620030715en00370055.pdf (29.01.2007).

Hadley, W.S.; VanDyke, J.W.; Stovall, T.K. (2005): Distributed Generation - Benefit values

in hard numbers, Utilities Fortnightly, April 2005, pp 46-53.

Haubrich, H.-J.; Hoffmann, J. (1995): Verteilung und Speicherung elektrischer Energie, IKARUS - Instrumente für Klimagasreduktionsstrategien, Teilprojekt 4, Forschungszentrum Jülich GmbH.

Haupt, U.; Kinnunen, K.; Pfaffenberger, W.: Anwendung der Vergleichsmarktanalyse auf die Netzentgelte in der Stromwirtschaft. Gutachten im Auftrag der EnBW AG, available under: http://www.bei.uni-bremen.de/pdf/veroff/enbw lang.pdf (05.10.2005)

Hufendiek (2001): Systematische Entwicklung von Lastprognosesystemen auf der Basis neuronaler Netze, VDI Fortschritt-Berichte Reihe 6 Energietechnik, Nr.455.

IEA (2002): Distributed Generation in Liberalised Electricity Markets. IEA books. Paris Joskow, P.L. (2005): Transmission policy in the United States, Utilities Policy Volume 13(2), Pages 95-115, 2005.

Kumar, A.; Srivastava, S.C.; Singh, S.N. (2005): Congestion management in competitive Power market: a bibliographical survey, Electric Power Systems Research, Volume 76, Issues 1-3, pp. 153-164.

Lehman, P. (2005): Development of an Electrolyzer enabling seasonal storage of renewable energy, Energy Innovation small grant program, available under: http://www.energy. ca.gov/2005publications/CEC-500-2005-085/CEC-5002005-085.PDF (05.10.2005).

Lovins, A.B. (2003): Small is profitable: The Hidden economic benefits of making electrical resources the right size, Refocus, Volume 4(3), p. 12, 2003.

Materazzi-Wagner, Ch. (2003): Long term perspectives for DG in Europe, draft-version, available under: http.www.dispower.de (29.07.2005).

Morse, J. (1997): Regulatory Policy Regarding Distributed Generation by Utilities: The Impact of restructuring, The Energy Journal, DR Special Issue, pp 187-210. Mühlstein, J. (2003): Vermiedene Netznutzungsentgelte der dezentralen Einspeisung, avai 
lable under: http://www.bkwk.de/download/politik/kurzgutachten.pdf (29.01.2007).

Newborough, M. (wo. y.): Domestic Electrical Demand and Micro-DSM. Available under:

www.umist.ac.uk/departments/civil/rearch/building/40percent/PDFs/MarcusN ewborough.pdf $(05.10 .2005)$.

Pepermans, G.; Driesen, J.; Haeseldonckxc, D.; Bellmen's, R.; D'Haeseleer, W. (2005): Distributed generation: definition, benefits and issues, Energy Policy 33 (2005) 787798.

Pfeifenberger, J.P.; Hanser, P.Q.; Ammann, P. (1997): What's the Cards for Distributed Resources?, The Energy Journal, DR Special Issue, pp 1-16.

Preston, G. T. and D. M. Rastler (1996) Distributed Generation: Competitive Threat or Opportunity? Public Utilities Fortnightly, 34(15), 13-17.

Raineri, R.; Rios, S.; Vasquez, R. (2005): Business opportunities and dynamic competition through distributed generation in primary electricity distribution networks, Energy Policy, Volume 33 (17), Pages 2191-2201, Santiago 2005.

Salerian, J.; Gregan, T.; Stevens, A. (2001): Pricing in Electricity markets, Journal of Policy modelling, Volume 22(7), pp. 859-893, 2000.

Salies, E.; Price, C. W. (2004) Charges, Costs and Market Power in the Deregulated UK Electricity retail market, the Energy Journal 25(3), 19-35.

Sander, K. (2004): Potenziale und Perspektiven stationärer Brennstoffzellen, Forschungsbericht des IER, Universität Stuttgart, Band 96, Stuttgart.

Scheepers, M.J.J. (2004): SUSTELNET - Policy and Regulatory Roadmaps for the Integration of Distributed Generation and the Development of Sustainable Electricity Networks, ECN-C--04-034, available under: http://www.ecn.nl/docs/library/report/2004/ c04034.pdf(25.07.2005)

Smeers, Y. (2005): Long term locational prices and investment incentives in the transmission of electricity, Center for operations research and econometrics Belgium, discussion paper 30-2005, Louvain-la-Neuve 2005.

Stoft, S. (2002): Power System Economics. Designing Markets for Electricity. New York VDN (2001a): Verbändevereinbarung über Kriterien zur Bestimmung von Netznutzungsentgelten für elektrische Energie und über Prinzipien der Netznutzung, available under:

http://www.vdnberlin.de/global/downloads/Publikationen/vv2plus.pdf (05.10.2005) 
VDN (2001b): Kommentarband der Verbändevereinbarung über Kriterien zur Bestimmung von Netznutzungsentgelten für elektrische Energie und über Prinzipien der Netznutzung, available under: http://www.vdn-berlin.de/global/downloads/ Publikationen/kommentarband vv2.pdf (05.10.2005).

Weber, C. (2006): Integrating electricity production from fluctuating sources - valuation of variability and unpredictability. Discussion paper EWL, University of DuisburgEssen.

Weber, C. Vogel, P. (2007): Assessing the benefits of a provision of system services by distributed generation, forthcoming in International journal of global energy issues.

Wohlgemuth, N. (2001): Network Industries and Technological Change Towards Sustainability: The Example of the Electricity Industry, Economics department University Klagenfurt, available under http://www.wifo.at/Stefan.Schleicher/down/diss/ HAB Wohlgemuth.pdf. (05.10.2005). 